\title{
Riqueza de morfoespécies de nematoides em áreas de olericultura em Palmas-PR
}

\author{
Bárbhara Talyssa MICHELS ${ }^{*}$, Eduarda Kalena Kirsch de RAMOS ${ }^{1}$, \\ Emi Rainildes LORENZETTI ${ }^{2}$, Leandro Alvarenga SANTOS ${ }^{3}$
}

\author{
${ }^{1}$ Instituto Federal do Paraná, Palmas, PR, Brasil. (ORCID: *; 000-0003-4325-4214) \\ ${ }^{2}$ Instituto Federal do Paraná, Campo Largo, PR, Brasil. (ORCID: *; 0000-0003-0867-095X) \\ ${ }^{3}$ Universidade Estadual de Feira de Santana, Feira de Santana, BA, Brasil. (ORCID: *; 0000-0003-0682-6949) \\ *E-mail: barbharamichels@gmail.com (ORCID: 000-0001-6632-8963)
}

Recebido em 21/10/2019; Aceito em 26/05/2020; Publicado em 10/06/2020.

\begin{abstract}
RESUMO: Os nematoides são animais invertebrados, multicelulares, constituintes de um grupo muito diversificado estimado em um milhão de espécies. As condições ecológicas do solo estão intimamente relacionadas com a sua biodiversidade. O objetivo deste trabalho foi realizar um levantamento da diversidade de espécies de fitonematoides em propriedades que atuam na área de olericultura em Palmas, no Estado do Paraná. As amostras de solo foram coletadas em quatro locais da cidade. Os locais amostrados são: área de mata nativa $(\mathrm{MN})$; propriedade olerícola em sistema de cultivo convencional com a utilização de agrotóxicos (A); duas propriedades de sistema de cultivo orgânico, uma localizada em área urbana (B) e a outra em área rural (C). A maior diversidade de gêneros de fitonematoides encontrados foi encontrada em ambas as propriedades de cultivo orgânico ( $\mathrm{C}$ e B, respectivamente), que não diferiram significativamente entre si, mas em relação à área de mata nativa $(\mathrm{MN})$ e a propriedade de sistema cultivo convencional $(\mathrm{A})$, nessa ordem. $\mathrm{O}$ número de nematoides assim como a diversidade de gêneros identificados foram maiores nas propriedades que exercem o sistema de cultivo orgânico.
\end{abstract}

Palavras-chave: horticultura; nematologia; sistemas de produção vegetal.

\section{Morphoespecies richness of nematoides in the olericulture areas in Palmas - PR}

\begin{abstract}
The nematodes are invertebrate, multicellular animals, constituents of a very diversified group estimated at one million species and the ecological conditions of the soil are closely related to their biodiversity. The objective of this paper is to perform a survey of the diversity of nematode species on properties that work with olericulture in Palmas, Paraná state. Soil samples were collected at four sites in the city, with a Cfb type climate (temperate, humid and mild summer). Among the sites sampled are: native forest area (MN); farm property with conventional farming system with the use of agrochemicals (A); two organic farming system properties, one located in urban area $(B)$ and the other in rural area $(C)$. The greatest diversity of phytonutrient genera found was found in both organic ( $\mathrm{C}$ and $\mathrm{B}$, respectively) properties, which did not differ significantly from each other, but in relation to the native forest area $(\mathrm{MN})$ and conventional cropping system $(\mathrm{A})$, in that order. The number of nematodes as well as the diversity of genera identified were higher in the properties that exert the organic cultivation system.
\end{abstract}

Keywords: horticulture; nematology; plant production systems.

\section{INTRODUÇÃO}

Os nematoides são animais invertebrados, geralmente microscópicos classificados como Filo Nematoda. Estimados em mais de um milhão de espécies (RITZINGER; FANCELLI, 2006), são animais multicelulares mais abundantes do mundo, constituindo um grupo muito diversificado, com diferentes papéis ecológicos no solo e formas com diferentes hábitos alimentares (GOULART, 2010), apresentando ainda uma densidade de aproximadamente 30 milhões $/ \mathrm{m}^{2}$ no mundo (FREITAS, 2009).

Por meio disso, os diferentes grupos compostos por nematoides são classificados como: fitoparasitas ou fitófagos, fungívoros ou micófagos, bacteriófagos, carnívoros ou predadores e onívoros, sendo a maioria, de vida livre (LOPES, 2015). Ainda não existem dados concretos sobre a área total infestada por fitonematoides no Brasil e no mundo, porém, as perdas de produção em culturas agrícolas causadas por eles são estimadas globalmente de 6,9 -50\% (SOUSA, 2016).

As condições ecológicas do solo estão intimamente relacionadas com a biodiversidade dos nematoides. Esses animais se movimentam entre as partículas e no filme de água, ou seja, por canais que tornam a movimentação mais dinâmica quando os mesmos apresentam diâmetro maior que o corpo dos nematoides (ARIEIRA, 2012). No solo, esses organismos possuem um papel importante como reguladores de processos essenciais, como a decomposição da matéria orgânica, o qual eleva as taxas de mineralização do carbono (respiração) e de outros nutrientes (NAZARENO, 2009; ARIEIRA, 2012).

Dessa forma, a atividade de fungos e bactérias sobre a decomposição da matéria orgânica é afetada por nematoides micófagos e bacteriófagos que se alimentam desses 
microrganismos, sincronizando, posteriormente, suas populações (VILLATORO, 2004).

A diversidade de nematoides também é estudada para avaliar a qualidade ou sanidade de solos, pois são bioindicadores na avaliação do impacto de atividades humanas e suas possíveis alterações ambientais (GOULART et al., 2009), além disso, áreas com variados níveis de intervenção humana, como por exemplo a aração, o uso de produtos químicos e áreas com intervenção de baixo impacto, influenciam de forma direta e/ou indireta a riqueza de nematoides no solo (FERRIS et al., 2012).

Os nematoides fitoparasitas (ou fitonematoides) são vermes que habitam no solo, águas marinhas ou águas doces e que atacam raízes de plantas ou qualquer outro órgão subterrâneo, resultando em sérios problemas às culturas agrícolas e prejuízos ao produtor rural. Todavia, os danos causados por esses organismos podem variar de acordo com a cultura estabelecida, pelo manejo da área e pelas características edafoclimáticas da região (LOPES, 2015). De acordo com Goulart (2010) os nematoides de maior importância agrícola no Brasil são: Meloidogyne spp. (nematoide das galhas), Pratylenchus spp. (nematoide das lesões radiculares), Heterodera glycines Ichinohe (nematoide dos cistos da soja), Rotylenchulus reniformir Linford \& Oliveira (nematoide reniforme) e Tylenchulus semipenetrans Cobb (nematoide dos citros).

A diferença básica que distingue os nematoides fitoparasitas do restante é a presença de um estilete na forma de agulha na cavidade bucal localizado na parte anterior da cabeça desses organismos (CHARCHAR, 1999). Esse estilete é introduzido nas raízes de plantas para a retirada de alimento, ao mesmo tempo em que é injetado substancias tóxicas com potencial de afetar os principais processos fisiológicos como a fotossíntese, a respiração, o balanço hormonal e a absorção de água e nutrientes (LOPES, 2015). Os fitonematoides na sua maioria possuem comprimentos que variam de 0,2 a $3 \mathrm{~mm}$, necessitando do auxílio de um microscópico para estudá-lo. Como resultado, muitos danos causados por esses organismos passam despercebidos, sendo atribuído outras causas para os sintomas, como por exemplo, a falta de nutrientes - ligada a fertilidade do solo (CHARCHAR, 1999).

$\mathrm{Na}$ olericultura, os fitonematoides podem interferir na produtividade em até $100 \%$, dependendo do grau de infestação da área, da espécie de nematoide envolvida, da cultivar utilizada e das condições ambientais. Esses casos são mais frequentes quando as hortaliças são cultivadas na mesma área, sem o uso de rotação de culturas, o qual auxilia como uma medida de controle cultural para inibir o desenvolvimento de espécies de nematoides de intenso ataque (PINHEIRO, 2012).

Estudos realizados na Arábia Saudita verificaram que entre diversos fitonematoides, o gênero Meloidogyne spp. apresentou a maior frequência de ocorrência e de densidade populacional em raízes de hortaliças (ALMOHITHEFA et al., 2018). Bonfim (2017) cita o nematoide das galhas como o principal responsável por perda de produtividade em hortaliças folhosas no Brasil, mas outros gêneros como o nematoide de lesões radiculares (Pratylenchus spp.), o cavernícola (Radopholus similis) e reniforme (Rotylenchulus reniformis) também estão relacionados com grandes prejuízos econômicos em cultivos de diversas culturas no país (COLTRO-RONCATO et al., 2015).
Deste modo, o controle de uma área infestada por esses organismos é realizado após o conhecimento sobre as espécies e a população. Isso se dá pela utilização de métodos de extração de nematoides, onde se podem obter dados quantitativos e qualitativos dos mesmos. A identificação desses animais é comumente baseada nas características morfológicas da população, feita através da utilização de um microscópico óptico e pela análise das amostras, possibilitando a diferenciação de espécies de nematoides benéficos e fitonematoides (MANSO; TENENTE, 1994).

Por não haver nenhum registro de levantamento nematológico na região, esse trabalho tem como objetivo avaliar a riqueza de gêneros de nematoides em propriedades olerícolas no município de Palmas - PR. Além disso, pretende-se verificar a influência das diferentes formas de manejo realizadas nas áreas produtoras sobre essa característica.

\section{MATERIAL E MÉTODOS}

As amostras de solo foram coletadas em quatro locais do município de Palmas - PR (Figura 1), que apresenta clima do tipo $\mathrm{Cfb}$, segundo a classificação climática de Köppen Geiger, ou seja, temperado, úmido e com verão ameno. Para esse clima se tem a média de temperatura menor que $18{ }^{\circ} \mathrm{C}$ no mês mais frio e maior que $22{ }^{\circ} \mathrm{C}$ no mês mais quente (IAPAR, 2018).

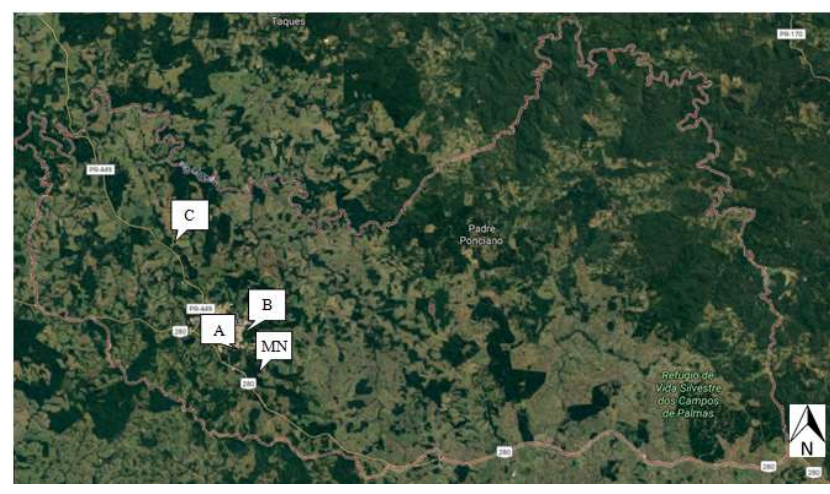

Figura 1. Vista de satélite do município de Palmas, localizado no estado do Paraná, indicando os onde estão estabelecidos os quatro locais de coleta. Fonte: Google Maps.

Figure 1. Satellite image of the municipality of Palmas, located in the state of Paraná, indicating where the collection sites are established. Source: Google Maps

Os locais amostrados foram:

- A área de mata nativa (Floresta Atlântica), sendo esse solo coletado na rizosfera de arbóreas, com a finalidade de incluir nas amostras uma área não cultivada (testemunha) MN (26³0'39.4"S 5159'10.5"W);

Uma propriedade que cultiva olerícolas em sistema convencional, com a utilização de agrotóxicos (fungicidas, inseticidas e herbicidas) e adubos minerais - A (26 $30^{\prime} 09.2^{\prime \prime} \mathrm{S}$ $\left.51^{\circ} 59^{\prime} 46.0^{\prime \prime} \mathrm{W}\right)$

- Duas propriedades que cultivam olerícolas em sistema de produção orgânica, uma localizada em área urbana - B $\left(26^{\circ} 29^{\prime} 15,7^{\prime \prime S} 51^{\circ} 59^{\prime} 12,5^{\prime \prime} \mathrm{W}\right)$ e a outra em área rural - C $\left(26^{\circ} 42^{\prime} 61^{\prime \prime S} 52^{\circ} 3^{\prime} 2^{\prime \prime} \mathrm{W}\right)$.

Cada amostra foi composta de solo coletado em três pontos próximos na profundidade de $0-10 \mathrm{~cm}$. No caso de 
$\mathrm{MN}$ foram retiradas de três árvores vizinhas e nos demais casos (A, B e C) em um mesmo canteiro. As amostras coletadas foram inicialmente preparadas nos laboratórios do IFPR - Campus Palmas de acordo com Jenkins (1964).

Com as amostras já homogeneizadas, foram retirados 50 $\mathrm{cm}^{3}$ de cada amostra e adicionada a 2L de água para que os torrões fossem desfeitos manualmente. Em seguida, as amostras de solo foram passadas em peneira de 20 mesh e por outra de 400 mesh acoplada, na parte inferior. O material retido na segunda peneira foi retirado com o uso de uma pisseta com água e transferido para um béquer.

O material obtido foi centrifugado por 5 minutos, e o líquido sobrenadante, descartado. Ao precipitado que restou nos tubos, adicionou-se solução de sacarose (para propiciar a suspensão dos nematoides por meio do aumento da densidade do meio) previamente preparada, na concentração de $454 \mathrm{~g} \mathrm{~L}^{-1}$. A mistura foi agitada, e novamente centrifugada, por 1 minuto a fim de realizar a coleta da solução sobrenadante. A solução obtida até então foi devidamente armazenada para transporte.

A mistura de sacarose armazenada foi vertida na peneira de 400 mesh para a retenção dos nematoides e em seguida lavada em água corrente para a retirada do excesso de sacarose das amostras. Os nematoides retidos na peneira, foram retirados com o auxílio de uma pisseta com água e colocados em um béquer, para sua posterior leitura no microscópio.

A leitura para identificação dos nematoides foi realizada em microscópio biológico invertido da marca Bel Photonics ${ }^{\circledR}$ no Laboratório de Fitopatologia da Unicentro Campus Cedeteg (Centro Educacional de Desenvolvimento Tecnológico de Guarapuava).

A partir de cada solução completa contendo os nematoides, foram extraídas com uma pipeta pequenas quantidades para a leitura na câmara de Peters, totalizando três repetições. Cada nematoide observado, através do microscópio foi fotografado para a posterior identificação.

A análise estatística dos dados obtidos foi feita a partir de análise variância e posteriormente teste de Tukey a 5\% de significância, utilizando o programa IBM SPSS Statistics 22. Os dados analisados estatisticamente foram: o número total de nematoides encontrados, o número de fitonematoides identificados, o percentual de fitonematoides em relação ao número total e o número de gêneros identificados.

A identificação das espécies de fitonematoides foi executada com base na literatura disponível (MAI; MULLIN, 1996).

\section{RESULTADOS}

O primeiro aspecto a ser analisado foi o número de nematoides, fitoparasitas ou não, contido em cada uma das três repetições dos locais $\mathrm{MN}, \mathrm{A}, \mathrm{B}$ e C. Considerou-se a média do número de nematoides totais encontrado nas três amostras analisadas (Figura 2).

Pelos dados observados foi possível verificar que o sistema de cultivo orgânico apresentou as maiores médias de incidência de nematoides sendo que apenas $B$ diferiu significativamente do número de nematoides observado em mata nativa e no sistema de cultivo convencional.

Outro parâmetro avaliado foi o número de nematoides fitoparasitas encontrados nas amostras, independentemente do gênero (Figura 3). Semelhantemente ao resultado observado no número de nematoides totais, os sistemas de cultivos orgânicos também apresentaram as maiores médias de fitonematoides, comparados ao sistema de cultivo convencional e ao da mata nativa. Nas áreas cujo sistema é de cultivo orgânico (B e C) foram observadas médias superiores àquelas observadas em mata nativa e no sistema convencional que não diferiram significativamente entre si.

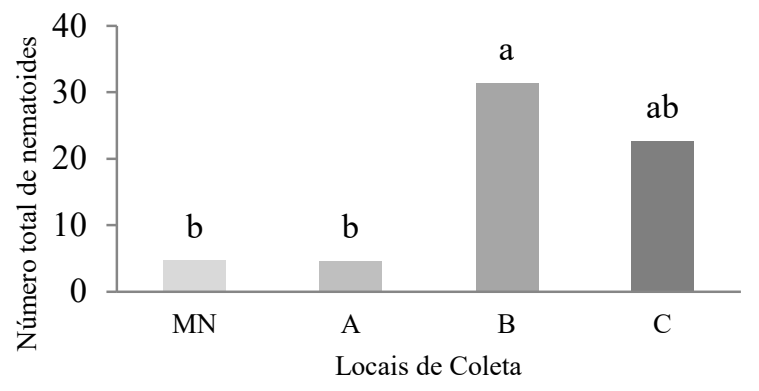

Figura 2. Dados representam médias do número total de nematoides de três amostras de solo de quatro áreas olerícolas diferentes: mata nativa (MN), sistema de cultivo convencional (A), sistema de cultivo orgânico em área urbana (B) e em área rural (C). Médias seguidas da mesma letra, não diferem entre si pelo teste de Tukey a $5 \%$ de significância.

Figure 2. Representative graph of the averages of the total number of nematodes from three soil samples, collected in four different vegetable areas: native forest $(\mathrm{MN})$, conventional cultivation system (A), organic cultivation system in urban area (B) and in rural area (C). Means followed by the same letter do not differ by Tukey's test at $5 \%$ significance.

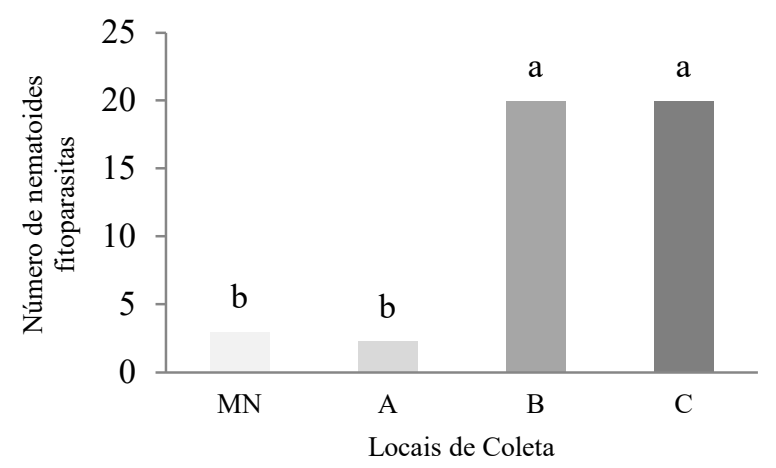

Figura 3. Número de fitonematoides classificados de acordo com as mostras obtidas em diferentes locais de produção de olerícolas no município de Palmas - PR (MN, A, B e C). Médias seguidas da mesma letra, não diferem entre si pelo teste de Tukey a $5 \%$ de significância.

Figure 3. Number of phytonematodes classified according to samples obtained at different vegetable production sites in the municipality of Palmas - PR (MN, A, B and C). Means followed by the same letter, do not differ by Tukey's test at 5\% significance.

Diferentemente de esperado, as amostras de mata nativa apresentaram menores índices de nematoides, indicando que o local de coleta pode estar sofrendo perturbações. Uma explicação pode ser a grande circulação de pessoas no ponto de coleta, que se localiza nas dependências do campus do IFPR. Também foram verificados os percentuais de nematoides fitoparasitas em relação ao total de nematoides encontrados por amostra. Entretanto, para essa análise não houve diferença significativa entre as médias, demonstrando 
que o aumento da população de fitonematoides não ocorre de forma igual entre os grupos.

A partir do levantamento realizado por este trabalho foi possível identificar 17 gêneros de fitonematoides nas diferentes amostras obtidas na cidade de Palmas (Tabela 1), sendo que apenas o gênero Hemicycliophora esteve presente em amostras das quatro áreas ( $\mathrm{MN}, \mathrm{A}, \mathrm{B}$ e $\mathrm{C}$ ). Com isso, podese perceber que os gêneros de fitonematoides se repetiam entre alguma das propriedades de cultivo orgânico (B e C).

Com a caracterização dos gêneros dos fitonematoides, observou-se que a maior diversidade de espécies de nematoides fitoparasitas foi vista nas duas áreas de olericultura orgânica (B e C), enquanto na área de mata nativa $(\mathrm{MN})$ e na propriedade de cultivo convencional (A), a variedade de gêneros foi bastante inferior (Figura 5). Isso mostra que o aumento populacional de fitonematoides implica no aumento na variedade de gêneros presentes nesse mesmo local.

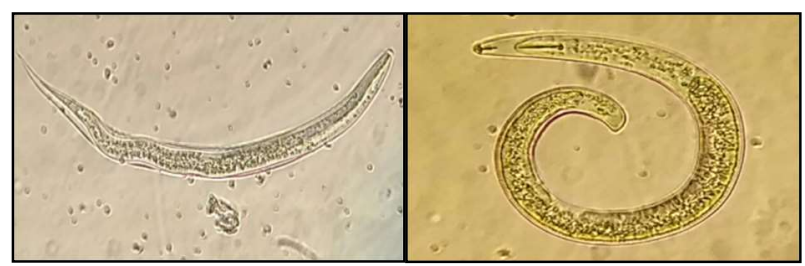

(A)

(B)

Figura 4. Imagens exibindo os gêneros de nematoides encontrados nas amostras e identificados através do uso de um microscópico óptico: (A) Hemicycliophora encontrado nas amostras MN, A, B e C; (B) Helicotylenchus presente nas amostras A, B e C.

Figure 4. Nematodes genera found in soil samples and identified using an optical microscope: (A) Hemicycliophora found in samples MN, A, B and C; (B) Helicotylenchus present in samples A, B and C.

Tabela 1. Distribuição classificativa de fitonematoides encontrados nas amostras coletadas no município de Palmas - PR de acordo com a chave de identificação Plant-parasitic nematodes: A pictorial key to general (MAI; MULLIN, 1996).

Table 1. Classification of the phytonematodes found in the samples collected in the city of Palmas - PR according to the identification key Plant-parasitic nematodes: A pictorial key to general (MAI; MULLIN, 1996).

\begin{tabular}{llccc}
\hline \multirow{2}{*}{ Generos } & \multicolumn{4}{c}{ Locais de Coleta } \\
\cline { 2 - 5 } & $\mathrm{MN}$ & $\mathrm{A}$ & $\mathrm{B}$ & $\mathrm{C}$ \\
\hline Aorolaimos & & & & $\mathrm{X}$ \\
Ditylenchus & & & $\mathrm{X}$ & \\
Dorylaimus & & & $\mathrm{X}$ & $\mathrm{X}$ \\
Helicotylenchus & & $\mathrm{X}$ & $\mathrm{X}$ & $\mathrm{X}$ \\
Hemicycliophora & $\mathrm{X}$ & $\mathrm{X}$ & $\mathrm{X}$ & $\mathrm{X}$ \\
Mesocriconema & & & $\mathrm{X}$ & \\
Paratrichodorus & & $\mathrm{X}$ & $\mathrm{X}$ & $\mathrm{X}$ \\
Paratylenchus & $\mathrm{X}$ & & $\mathrm{X}$ & $\mathrm{X}$ \\
Pratylenchus & $\mathrm{X}$ & & $\mathrm{X}$ & $\mathrm{X}$ \\
Radopholus & & $\mathrm{X}$ & & \\
Rotylenchulus & & & $\mathrm{X}$ & $\mathrm{X}$ \\
Rotylenchus & & $\mathrm{X}$ & $\mathrm{X}$ & $\mathrm{X}$ \\
Scutellonema & & & $\mathrm{X}$ & $\mathrm{X}$ \\
Tylenchorbynchus & & & $\mathrm{X}$ & $\mathrm{X}$ \\
Tylenchulus & & $\mathrm{X}$ & $\mathrm{X}$ & $\mathrm{X}$ \\
Tylenchus & $\mathrm{X}$ & & $\mathrm{X}$ & $\mathrm{X}$ \\
Xipbinema & & &
\end{tabular}

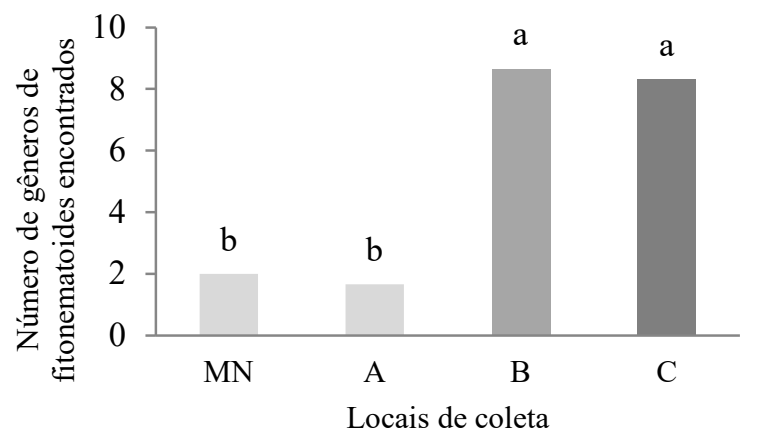

Figura 5. Número de gêneros de fitonematoides identificados por meio da leitura das amostras $\mathrm{MN}, \mathrm{A}, \mathrm{B}$ e C com três repetições cada através da visualização com microscópico eletrônico invertido.

Médias seguidas da mesma letra, não diferem entre si pelo teste de Tukey a $5 \%$ de significância.

Figure 5. Number of phytonematodes genus identified by reading samples $\mathrm{MN}, \mathrm{A}, \mathrm{B}$ and $\mathrm{C}$ with three repetitions each through visualization with an inverted electron microscope. Means followed by the same letter, do not differ by Tukey's test at $5 \%$ significance.

\section{DISCUSSÃO}

É possível afirmar que a taxa de aparecimento de nematoides é influenciada pelo nível de perturbação ambiental. Isso indica que a intensidade das alterações em seus habitats pode ocasionar a diminuição da população (GOEDE; BONGERS, 1993). Isso justifica a diferença notável entre o total de nematoides entre A (de sistema convencional de cultivo) das propriedades cujo sistema de cultivo é orgânico.

A maior incidência de nematoides totais e fitonematoides observado nos dois sistemas de cultivo orgânicos, comparados ao sistema convencional e mata nativa, podem estar relacionados à maior diversidade de plantas hospedeiras presentes nesta forma de cultivo, uma vez que cultivo orgânico não utiliza remoção de todas as plantas concorrentes durante o ciclo da olerícola ou ainda por este sistema usar como prática de manejo, o pousio que permite maior diversidade de plantas espontâneas que podem servir posteriormente como hospedeiras (ROSSI et al., 2011). Entre as plantas mais comuns que atuam como hospedeiras para os nematoides estão: Ipomoea acuminata (corda-de-viola), Amaranthus bybridus var. Patulus (caruru), Alternaria ficoidea (apaga-fogo) e Commelina virginica (trapoeraba) (CARMO; SANTOS, 2008).

Outro fator que pode estar atribuído a incidência de nematoides, é o uso de adubação como uma tática de controle desses organismos, pois promove melhorias nas características físicas, químicas e biológicas do solo, favorecendo também a tolerância da planta a ataques de fitonematoides através de sua nutrição. Sendo assim, as técnicas de cultivo orgânico integradas com manejo da área podem promover queda na população de fitonematoides nesses sistemas (MORAES et al., 2006).

Resultados obtidos por Figueira et al. (2011) ao comparar a estrutura de população de nematoides em solos com quatro sistemas diferentes de manejo (pasto, horta, capoeira e figo consorciado com Paspalum notatum), indicou aumento da população de nematoides bacteriófagos no sistema horta, enquanto a população total de fitonematoides 
foi maior em sistema pasto com dominância também em sistema horta.

Os dados obtidos são similares aos encontrados por Sgrignoli et al. (2014), quando indicou a presença de grande infestação de nematoides do gênero Hemicycliophora nas amostras nematológicas. A frequência do aparecimento de Hemicycliophora sp. se dá pela sua extensa distribuição geográfica, enquanto o gênero Helicotylenchus, presente nas amostras dos ambientes A, B e C, é caracterizado por ser um nematoide frequente e abundante no Brasil, com uma ampla distribuição em várias culturas como é mostrado também por Sgrignoli et al. (2014).

O número de gêneros de fitonematoides está proporcionalmente ligado à biodiversidade do ambiente no qual está inserido. Dados descritos por Goulart et al. (2003) indicam que os gêneros de fitonematoides são maiores em áreas de vegetação nativa do que em áreas cultivadas, demonstrando dados antagônicos ao observado acima. Todavia, a densidade populacional desses fitonematoides é menor que em áreas de cultivo.

A diversidade de nematoides em uma área é refletida pelas variações que ocorrem na comunidade, sendo alterada pelas diversas mudanças ambientais, seja elas por ação antrópica ou da natureza. Com isto, quanto menor o distúrbio no ecossistema, maior a diversidade e população de fitonematoides na área (RITZINGER et al., 2010). Embora as condições ambientais venham favorecer a permanência de fitonematoides, Oka (2010) cita a ação da matéria orgânica como nematicida e substrato para o crescimento de outros organismos que podem controlar ou limitar esses nematoides, além de atribuir melhores condições de fertilidade no solo para a planta.

Por fim, diversos estudos relacionados ao controle de fitonematoides pelo uso de adubação orgânica mencionam, que a redução da população de nematoides nem sempre está relacionada pela adição de matéria orgânica, mas pelo efeito da adubação em propiciar melhores condições nutricionais para a planta tornando-a mais tolerante ao ataque de nematoides e consequentemente aumentando a resposta positiva da cultura em termos de produtividade (SILVA et al., 2006; OLIVEIRA et al., 2005). Com as melhores condições encontradas para as plantas, os sintomas causados por fitonematoides nem sempre são evidentes a campo, possibilitando que a produção seja satisfatória mesmo na presença desses organismos.

Há alguns pontos importantes que merecem maiores investigações como o aumento proporcional do número de indivíduos e do número de gêneros encontrados nas amostras e as populações de nematoides existentes na Mata Atlântica. No caso da mata nativa, é necessária a realização de maiores estudos para verificar se a baixa frequência dos nematoides nessas áreas é ou não variável.

\section{CONCLUSÕES}

De acordo com o levantamento realizado, é possível afirmar que propriedades que exercem o sistema de cultivo orgânico são mais ricas em gêneros de fitonematoides quando comparadas ao sistema de cultivo convencional. Essa diferença tão evidente reforça que as práticas de cultivo adotadas na olericultura interferem na biodiversidade dos nematoides.
Ainda existe a necessidade de maiores investigações em relação a levantamentos nematológicos nas diferentes culturas. Deste modo, é fundamental a realização de maiores levantamentos visando à caracterização das populações de nematoides existentes na mata nativa da região, de modo a se obter parâmetros mais concretos sobre esse bioma.

\section{REFERÊNCIAS}

ALMOHITHEFA, A. H.; Al-YAHYAA, F. A.; AlHAZMIA, A. S.; DAWABAHB, A. A.; LAFI, H. A. Prevalence of plant-parasitic nematodes associated with certain greenhouse vegetable crops in Riyadh region, Saudi Arabia. Journal of the Saudi Society of Agricultural Sciences, v. 19, n. 1, p. 22-25, 2020. DOI: httpss://dx.doi.org/10.1016/j.jssas.2018.05.001

ARIEIRA, G. D. Diversidade de nematoides em sistemas de culturas e manejo do solo. 2014. 64f. Dissertação (Mestrado) - Universidade Estadual de Londrina, Londrina, 2014. Disponível em: < http://www2.unemat.br/ppgasp/dissertacoes/2014_fra ncieli.pdf> Acesso em: 5 nov 2018.

BONFIM, C. O. Fitonematoides associados ao cultivo de hortaliças no município de Lagoa Seca-PB. 2017. 33 f. Trabalho de Conclusão de Curso (Graduação em Agronomia) - Univesidade Federal da Paraíba, 2017. Disponível em: < https://repositorio.ufpb.br/jspui/handle/123456789/4 355> Acesso em: 23 nov 2018.

CARMO, D. B.; SANTOS, M. A. Hospedabilidade de plantas infestantes aos fitonematoides Meloidogyne Javanica e Pratylenchus Brachyurus. In: Encontro Interno, 8.; Seminário de Iniciação Científica, 7., 2008, Uberlândia. Anais... Uberlândia: Universidade Federal de Uberlândia, 2008. não paginado. Disponível em: < https://ss14799.websiteseguro.com/swge5/seg/cd2008 /PDF/IC2008-0394.PDF> Acesso em: 28 nov 2018.

CHARCHAR, J. M. Nematoides em hortaliças. Brasília: Embrapa Hortaliças, 1999. 12 p. (Circular técnica, 18). Disponível em:

https://www.infoteca.cnptia.embrapa.br/bitstream/doc /768139/1/CNPHDOCUMENTOS18NEMATOIDE SEMHORTALICAS.pdf > Acesso em: 5 nov 2018.

COLTRO-RONCATO, S.; GONÇALVES, E. D.; DILDEY, O. D.; KUHN, O. J.; STANGARLIN, J. R. Fitoquímicos como controle alternativo de nematoides. In: KUNH, O. J.; NUNES, R. V.; STANGARLIN, J. R.; FEY, R.; COSTA, N. V. da; COSTA, P. B.; GUIMARÃES, V. F.; ZAMBOM, M. A. (Org.). Ciências Agrárias: Tecnologias e Perspectivas. Marechal Cândido Rondon: Universidade Estadual do Oeste do Paraná, 2015. p. 188-206.

FERRIS, H.; GRIFFITHS, B. S.; PORAZINSKA, D. L.; POWERS, T. O.; WANG, K.-H.; TENUTA, M. Reflections on plant and soil nematode ecology: Past, Present and Future. Journal of Nematology, College Park, v. 44, n. 2, p. 115-126, 2012.

FIGUEIRA, A. F.; BERBARA, R. L.; PIMENTEL, J. P. Estrutura da população de nematoides do solo em uma unidade de produção agroecológica no Estado do Rio de Janeiro, Brasil. Acta Scientiarum. Agronomy, Maringá, v. 33 , n. 2, p. 223-229, 2011. DOI: https://dx.doi.org/10.4025/actasciagron.v33i2.4716 
FREITAS, L. G. Introdução à nematologia. Viçosa: Editora UFV, 2009. 84 p.

GOEDE, R. G. M.; BONGERS, T. Nematode community structure in relation to soil and vegetation characteristics. Applied Soil Ecology, Amsterdam, v. 1, n. 1, p. 39-40, 1994. DOI: https://dx.doi.org/10.1016/09291393(94)90021-3

GOULART, A. M. Análise Nematológica: importância e princípios gerais. Brasília: Embrapa Cerrados, 2010. 47 p. (Documentos, 299).

GOULART, A. M.; CARES, J. E.; FERRAZ, L. C. Ecologia e biodiversidade de nematoides: parte 1. RAPP - Vol. 17. Sociedade Brasileira de Fitopatologia, 2009. 163 p.

GOUlART, A. M.; MONTEIRO, A. R.; FERRAZ, L. C. Comunidades de nematoides em Cerrado com vegetação original preservada ou substituída por culturas. 2. Diversidade taxionômica. Nematologia Brasileira, Campinas, v. 27, n. 2, p. 129-137, 2003.

IAPAR_INSTITUTO AGRONÔMICO DO PARANÁ. Cartas Climáticas do Paraná - Classificação Climática. 2018, p. 149-188.

JENKINS, W. R. A rapid centrifugal-flotation technique for separating nematodes from soil. Plant Disease Report, Saint Paul, v. 48, n. 4, p. 692, 1964.

LOPES, C. M. Populações de nematoides fitoparasitas em áreas de cultivo de soja, algodão, café e de vegetação nativa do cerrado na região oeste da Bahia. 2015. 70f. Dissertação (Mestrado) - Univesidade de Brasília, Brasília, 2015.

MAI, W. F.; MULLIN, P. G. Plant-parasitic nematodes: A pictorial key to genera. 5. ed. Ithaca: Cornell University Press, 1996. 288 p.

MANSO, E. C.; TENENTE, R. V. Extração e identificação de fitonematoides. RAPP, v. 2, p. 265-291, 1994.

MORAES, S. R.; CAMPOS, V. P. POZZA, E. A.; FONTANETTI, A.; CARVALHO, G. J.; MAXIMINIANO, C. Influência de leguminosas no controle de fitonematoides no cultivo orgânico de alface americana e repolho. Fitopatologia Brasileira, Brasília, v. 31, n. 2, p. 188-191, 2006. DOI: http://dx.doi.org/10.1590/S0100-41582006000200011

NAZARENO, G. G. Utilização da matéria orgânica no controle de nematoide das galhas em alface sob cultivo protegido. Bioscience Journal, Uberlândia, v. 26, n. 4, p. 579-590, 2010.

OKA, Y. Mechanisms of nematode suppression by organic soil amendments - A review. Applied Soil Ecology, Amsterdam, v. 44, n. 2, p. 101-115, 2010. DOI: https://dx.doi.org/10.1016/j.apsoil.2009.11.003

OLIVEIRA, F. C.; ROCHA, M. R.; REIS, A. J. S.; MACHADO, V. O. F.; SOARES, R. A. B. Efeito de produtos químicos e naturais sobre a população de nematoide Pratylenchus brachyurus na cultura da cana-deaçúcar. Pesquisa Agropecuária Tropical, Goiânia, v. 33, n. 3, p. 171-178, 2005.

PINHEIRO, J. B. Ocorrência e manejo de nematóides em hortaliças. Brasília - DF: Embrapa, 2012. 1 p. Disponível em: https://ainfo.cnptia.embrapa.br/digital/bitstream/item /160780/1/digitalizar0198.pdf> Acesso em: 8 nov 2018.

RITZINGER, C. H.; FANCELLI, M. Manejo integrado de nematoides na cultura da bananeira. Revista Brasileira de Fruticultura, Jaboticabal, v. 28, n. 2, p. 331-338, 2006.
DOI: http:/ /dx.doi.org/10.1590/S010029452006000200041

RITZINGER, C. H.; FANCELLI, M.; RITZINGER, R. Nematoides: Bioindicadores de sustentabilidade e mudanças edafoclimáticas. Revista Brasileira de Fruticultura, Jaboticabal, v. 32, n. 4, p. 1289-1296, 2010. DOI: http://dx.doi.org/10.1590/S010029452010000400045

ROSSI, C. E.; PURQUERIO, L. F.; NEVES, S. S. Adubação verde para controle de nematoides em cultivo de alface em ambiente protegido. Horticultura Brasileira, Brasília, v. 29, n. 2, p. 1463-1468, 2011.

SGRIGNOLI, L. A.; ALMEIDA, A. G.; OLIVEIRA, A. D.; OTOBONI, A. M.; PARDO, R. B.; MARINELLI, P. S.; OTOBONI, C. E. Análise química do solo e levantamento de fitonematoides em hortas do município de Marília/SP. Revista Científica Eletrônica de Agronomia, Garça, v. 25, n. 1, p. 1-16, 2014.

SILVA, M. G.; SHARMA, R. D.; JUNQUEIRA, A. M.; OLIVEIRA, C. M. Efeito da solarização, adubação química e orgânica no controle de nematóides em alface sob cultivo protegido. Horticultura Brasileira, Brasília, v. 24 , n. 4, p. 489-494, 2006. DOI: http://dx.doi.org/10.1590/S0102-05362006000400019

SOUSA, A. J. J. Espécies de Meloidogyne em hortaliças e outras culturas provenientes de áreas periurbanas da África Subsaariana. 2016. 93f. Dissertação (Mestrado) - Universidade de Brasília, Brasília, 2016. Disponível em: <http:/ / repositorio.unb.br/handle/10482/20916> Acesso em: 8 nov 2018.

VILLATORO, M. A. Matéria orgânica e indicadores biológicos da qualidade do solo na cultura do café sob manejo agroflorestal e orgânico. Seropédica - Rio de Janeiro: UFRRJ, 2004. 176f. Tese (Doutorado) Universidade Federal Rural do Rio de Janeiro, Seropédica, 2004. Disponível em: <http://www.sbicafe.ufv.br/bitstream/handle/1234567 89/504/166723f.pdf?sequence $=1>$ Acesso em: 5 nov 2018. 